Gut, 1969, 10, 628-630

\title{
Excretion of 4-hydroxy-3 methoxy mandelic acid in cases of ulcerative colitis and diarrhoea of nervous origin
}

\author{
J. T. WRIGHT AND A. K. DAS \\ From the Department of Gastroenterology, The London Hospital
}

SUMMARY Urinary excretion of 4-hydroxy-3 methoxy mandelic acid (VMA) was used as an index of catecholamine activity in 59 cases of ulcerative colitis compared with 59 controls and 18 cases of diarrhoea of nervous origin. No significant differences were observed between cases and controls but the level of VMA excretion was raised in nervous diarrhoea.

The cause of ulcerative colitis is unknown, but relapses are commonly related to emotional trauma, and, since catecholamine excretion has often been used to measure the effect of emotional tension (Elmadjian, Hope, and Lamson, 1957; Byers, Friedman, Roseman, and Freed, 1962; Levi, 1963; von Euler, 1964; Hames, Lichtman, and McDonough, 1965; Nestel, Verghese, and Lovell, 1967), we have studied the excretion of 4 hydroxy-3 methoxy mandelic acid (VMA) in this disease.

\section{METHOD}

Thirty-five men and 24 women with ulcerative colitis were studied over a period of up to three-and-a-half years in some cases. The cases divided conveniently into two approximately equal age groups, 15 to 39 and 40 to 64 years. A control series matched for age and sex was also studied. Furthermore, during the course of this work similar observations were made on 18 patients with 'nervous' diarrhoea; the diagnosis in these cases was made largely by exclusion, there being no radiological or sigmoidoscopic abnormality and no evidence of infection, endocrine disorder, or malabsorption syndrome; on the other hand all cases had a positive history of nervous tension.

Most of the observations were made on urine samples passed on arrival at a morning gastroenterological clinic, although some 24-hour urine specimens were examined in the event of patients being admitted to hospital. The control series was drawn from patients with other gastroenterological disorders, mainly peptic ulcers, attending the same clinic. The object of this study was to determine whether colitis patients show differences in VMA excretion compared with patients suffering from other gut disorders in many of whom abnormal emotional tension may prevail. Results are expressed in mg/VMA per gram of creatinine.
Urine specimens were acidified to $p \mathrm{H} 1$ as soon as possible after collection and VMA was measured by a modification of Pisano's method (Connellan and Godfrey, 1964). Creatinine was estimated by the method of Bonsnes and Taussky's (1945).

The orange colour of the urine in patients receiving salazopyrin did not appear to affect the results of either VMA or creatinine assays. Other drugs used, including steroids, ACTH, barbiturates, codeine, and phenothiazines, appeared to have no direct effect on results. Duplicate estimations showed a mean difference of only $4 \%$ between pairs.

\section{RESULTS}

Excretion rates for VMA ranged from $0.90 \mathrm{mg} / \mathrm{g}$ creatinine to $11.9 \mathrm{mg} / \mathrm{g}$ creatinine but in individuals on whom repeated observations were made variation was relatively slight (Fig. 1 and Table I).

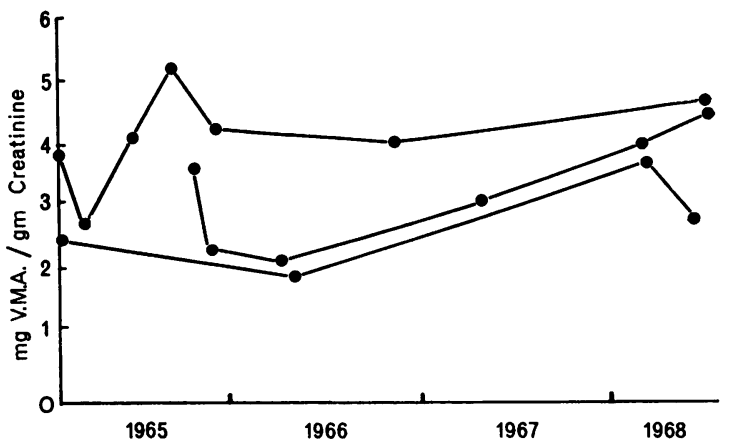

FIG. 1. Urinary VMA/creatinine ratios in three patients with ulcerative colitis studied over a long period. 
TABLE I

COEFFICIENT OF VARIATION IN VMA/CREATININE VALUES IN INDIVIDUAL PATIENTS

\begin{tabular}{ccc} 
No. of Observations & No. of Patients & $\begin{array}{c}\text { Coefficient of Variation } \\
(\%)\end{array}$ \\
\hline 9 & 1 & 26 \\
8 & 1 & 43 \\
7 & 1 & 31 \\
6 & 1 & 35 \\
5 & 3 & 32 \\
4 & 8 & 41 \\
3 & 13 & 23 \\
2 & 14 & 24
\end{tabular}

TABLE II

MEAN URINE VMA/CREATININE RATIOS IN CONTROLS AND IN PATIENTS WITH ULCERATIVE COLITIS AND 'NERVOUS' DIARRHOEA

\begin{tabular}{|c|c|c|c|c|}
\hline & \multicolumn{4}{|c|}{ Age Group (yr) } \\
\hline & \multicolumn{2}{|l|}{15 to 39} & \multicolumn{2}{|l|}{40 to 64} \\
\hline & Male & Female & Male & Female \\
\hline & $(15)^{1}$ & (10) & (20) & (14) \\
\hline Controls & $3 \cdot 1 \pm 0 \cdot 30$ & $3 \cdot 4 \pm 0.19$ & $3 \cdot 28 \pm 0.31$ & $4.0 \pm 0.43$ \\
\hline $\begin{array}{l}\text { Ulcerative } \\
\text { colitis }\end{array}$ & $\begin{array}{l}(18) \\
3 \cdot 2 \pm 0.39\end{array}$ & 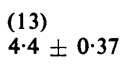 & $\begin{array}{l}(17) \\
3.66 \pm 0.39\end{array}$ & $\begin{array}{l}(11) \\
5 \cdot 1 \pm 0 \cdot 49\end{array}$ \\
\hline $\begin{array}{l}\text { 'Nervous' } \\
\text { diarrhoea }\end{array}$ & $0^{2}$ & $\begin{array}{l}(4) \\
5 \cdot 8 \pm 1 \cdot 5\end{array}$ & $\begin{array}{l}(4) \\
4 \cdot 5 \pm 1 \cdot 1\end{array}$ & $\begin{array}{l}(10) \\
6.9 \pm 0.81\end{array}$ \\
\hline
\end{tabular}

${ }^{1}$ Figures in parentheses show numbers of cases in subgroups ${ }^{2}$ Standard error of mean

Under the circumstances the mean VMA excretion for each group of patients has been compiled from the sum of the mean values for each patient. Table II compares mean VMA excretion rates in the various groups of patients studied. Mean VMA creatinine ratios are higher in women than in men and in both sexes higher in the older than in the younger age group. These differences are likely to be due to lower excretion of creatinine in women than men and in the elderly as compared with the young. Compared with the controls, the ratio is slightly higher in colitis patients and considerably higher in the nervous diarrhoea group.

The inequality of subgroups and other uncontrolled variables inherent in a pilot study of this sort prohibits formal statistical testing of the results but a trial series of analysis of variance was nevertheless performed (Table III). This shows that differences exist between the groups that are unlikely to be due to chance and that these are dependent on the diagnosis, age, and sex of the individual. It is unfortunately impossible to say what is the individual contribution of each of these factors except that the difference between the values for nervous diarrhoea and the controls is indeed likely to be due to the diagnostic difference between these groups.
TABLE III

SERIAL ANALYSIS OF VARIAINCE

\begin{tabular}{|c|c|c|c|c|c|}
\hline Source & $d f$ & $\begin{array}{l}\text { Sum of } \\
\text { the Squares }\end{array}$ & Variance & $F$ & $\boldsymbol{P}$ \\
\hline $\begin{array}{l}\text { Groups } \\
\text { Error }\end{array}$ & $\begin{array}{r}10 \\
125\end{array}$ & $\begin{array}{l}149 \cdot 12 \\
235 \cdot 14\end{array}$ & $\begin{array}{r}14.91 \\
1.88\end{array}$ & 7.93 & $<0.01$ \\
\hline $\begin{array}{l}\text { Diagnosis } \\
\text { Error }\end{array}$ & $\begin{array}{r}2 \\
133\end{array}$ & $\begin{array}{l}103 \cdot 02 \\
218 \cdot 24\end{array}$ & $\begin{array}{r}51 \cdot 51 \\
2 \cdot 11\end{array}$ & $24 \cdot 41$ & $<0.01$ \\
\hline $\begin{array}{l}\text { Sex } \\
\text { Error }\end{array}$ & $\begin{array}{r}1 \\
134\end{array}$ & $\begin{array}{r}55 \cdot 09 \\
329 \cdot 17\end{array}$ & $\begin{array}{r}55.09 \\
2.46\end{array}$ & $22 \cdot 39$ & $<0.01$ \\
\hline $\begin{array}{l}\text { Age } \\
\text { Error }\end{array}$ & $\begin{array}{r}1 \\
134\end{array}$ & $\begin{array}{r}18 \cdot 58 \\
365 \cdot 68\end{array}$ & $\begin{array}{r}18 \cdot 58 \\
2 \cdot 73\end{array}$ & $6 \cdot 81$ & $\doteqdot 0.01$ \\
\hline Total & 135 & $384 \cdot 26$ & & & \\
\hline
\end{tabular}

Many of the colitis patients in this series were already under treatment when the study began and few have had serious relapses. Opportunities for making observations in individual patients in both active and quiescent phases have therefore been few, but in 14 out of 20 such cases VMA/creatinine ratios were slightly higher in relapse than in quiescence and in one there was no difference. In two of the remaining six cases the value observed during quiescence was more than double that during activity of the disease, but both values were based on single estimations.

\section{DISCUSSION}

Raised VMA excretion in 'nervous' diarrhoea may be only a concomitant feature indicating release of adrenaline from the adrenal medulla as a response to stress or it may indicate a direct neuro-humoral mechanism involving liberation of noradrenaline from sympathetic nerve endings.

Theoretically adrenergic activity in the smooth muscle of the gut is inhibitory, but, as many recent studies have shown that diarrhoeal states are often associated with such inhibition, the theory is quite compatible with the facts. This aspect of the problem might have been clarified by estimation of the catecholamines themselves or of the intermediate breakdown products, 3 methoxy-adrenaline and 3 methoxy-noradrenaline. The disadvantage of studying these substances is their great lability in excretion levels. By measuringVMA excretion, which, as von Euler (1964) observes, is a sluggish index of catecholamine activity, we hope to reduce variation in urine levels consequent upon the immediate stress of attendance at hospital.

We have been unable to show convincing differences in catecholamine activity of colitis patients compared with controls but the general trend of the results suggests that the subject justifies further study. Increased catecholamine excretion is of course not confined to a group of cases with 'nervous' 
diarrhoea; several of the colitcs in whom nervous stress was obvious also had high VMA excretion rates. However, further experience may show that a high VMA excretion rate is of some diagnostic value in cases of diarrhoea for which there is no obvious physical cause.

We are indebted to the Board of Governors of The London Hospital who provided facilities for this research.

\section{REFERENCES}

Bonsnes, R. W., and Taussky, H. H. (1945). On the colorimetric determination of creatinine by the Jaffe reaction. J. biol. Chem. 158, 581-591.

Byers, S. O., Friedman, M., Rosenman, R. H., and Freed, S. C. (1962) Excretion of 3-methoxy-4-hydroxymandelic acid in men with behaviour pattern associated with high incidence of coronary artery disease. Fed. Proc., 21, suppl. 11, 99-101.

Connellan, T. P., and Godfrey, J. M.(1964). The routine determination of urinary 4-hydroxy-3-methoxy mandelic acid. Clin. chim. Acta, 9, 410-412.

Elmadjian F., Hope, J. M., and Lamson, E. T. (1957). Excretion of epinephrine and norepinephrine in various emotional states. J. clin. Endocr., 17, 608-620.

von Euler, (1964). Quantitation of stress by catecholamine analysis. Clin. Pharmacol. Ther., 5, 398-404.

Hames, C. G., Lichtman, M. A., and McDonough, J. R. (1965). Postexercise plasma and urinary norepinephrine and epinephrine levels among high social class and low social class males and subjects with nonacute coronary heart disease in Evans County, Georgia. (Abstr.), Circulation, 32, suppl. 2, 105.

Levi, L. (1963). The urinary output of adrenalin and noradrenalin during experimentally induced emotional stress in clinically different groups. Acta. psychother. (Basel), 11, 218-227.

Nestel, P. J., Verghese, A., and Lovell, R. R. H. (1967). Catecholamine secretion and sympathetic nervous responses to emotion in men with and without angina pectoris. Amer. Heart, J., 73, 227-234. 